Check for updates

Cite this: RSC Adv., 2017, 7, 38911

Accepted 25th July 2017

DOI: $10.1039 / c 7 r a 05790 c$

rsc.li/rsc-advances

\section{Selection of affinity peptides for the purification potential of porcine circovirus type 2 (PCV2) Cap virus-like particles (VLPs) $\uparrow$}

\author{
Guanmin Zheng, (D) ab Qingxia Lu, ${ }^{\text {b }}$ Fangyu Wang, ${ }^{\mathrm{b}}$ Qianyue Jin, ${ }^{\mathrm{b}}$ Man Teng, \\ Nana Zhang, ${ }^{\mathrm{b}}$ Tingting Ren, ${ }^{\mathrm{ab}}$ Peiyang Ding ${ }^{\mathrm{b}}$ and Gaiping Zhang ${ }^{\star a b}$
}

In this study, we describe the use of a M13 phage-displayed random peptide library for screening novel peptide motifs that specifically recognize recombinant PCV2 Cap protein for the first time. The peptide had a sequence of YHDCFSAGFCIG, and the binding affinity was observed in the nanomolar range. In the serum blocking test, the ELISA signal of the peptide was rapidly decreased when the concentration of the PCV2 positive serum was increased.
Porcine circovirus type 2 (PCV2) is a circular, single-stranded DNA virus. It is considered as the major pathogen of porcine circovirus associated-diseases (PCVAD) that causes huge economic losses for the swine industry around the world every

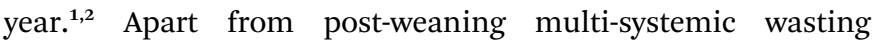
syndrome (PMWS), PCVAD also include porcine dermatitis and nephropathy syndrome (PDNS), ${ }^{3}$ reproductive disorders, porcine respiratory disease complex (PRDC) ${ }^{4}$ nervous system lesions, ${ }^{5}$ enteritis, ${ }^{6,7}$ and proliferative and necrotizing pneumonia (PNP). ${ }^{8}$ There are three major open reading frames (ORFs) in the PCV2 genome. First, ORF1 encodes a replicationassociated protein (Rep and Rep'), which is essential for the replication of viral DNA in host cells..,10 Second, ORF2 encodes the capsid, which is a unique structure protein (Cap) and main antigenic determinant of PCV2. ${ }^{11}$ The canonical viral jelly-roll structure of PCV2 Cap was identified via its crystal structure and cryo-electron microscopy (cryo-EM) image. ${ }^{12,13}$ Finally, ORF3 encodes a protein that is not essential for PCV2 replication, but may have an apoptotic effect on PCV2-infected cells. ${ }^{14,15}$ To date, safe and effective vaccines are considered as the best control measure for PCVAD. Virus-like particles (VLPs) formed by recombinant ORF2 expressed in prokaryotic as well as eukaryotic systems are similar to the intact PCV2 particles and have been utilized as a key constituent in vaccine formulation and have protected pigs against the infection of PCV2. Currently, the common purification process for PCV2 Cap VLPs

${ }^{a}$ College of Animal Husbandry and Veterinary Science, Henan Agricultural University, Zhengzhou 450002, People's Republic of China. E-mail: zhanggaiping2003@163.com ${ }^{b}$ Key Laboratory of Animal Immunology of the Ministry of Agriculture, Henan Provincial Key Laboratory of Animal Immunology, Henan Academy of Agricultural Sciences, Huayuan Road No. 116, Zhengzhou 450002, People's Republic of China. E-mail: luqingxia82@163.com

$\dagger$ Electronic supplementary information (ESI) available: Experimental details including biopanning of M13 phage. See DOI: 10.1039/c7ra05790c includes ultracentrifugation in $\mathrm{CsCl}$ or sucrose gradients and ion-exchange chromatography; ${ }^{16-19}$ however, these methods are uneconomic and waste time and energy.

A high antigen purity is an indicator of good vaccines; however, the purification takes a most part of the vaccine production cost. To improve the purification method and reduce the cost of PCV2 Cap VLPs, a simple, rapid, and effective purification method should be established. Recently, magnetic nanoparticles (MNPs) have been used as a carrier for purification due to their rapid and convenient magnetic control effects, intrinsically large loading capacity, and ease for functional modification..$^{20,21}$ The surfaces of MNPs are usually modified with biological affinity ligands for targeting. Antibodies show high specificity and target diversity, but their complex structure results in high production costs, low shelf-life, and problems related to degradation, modification, aggregation and/or denaturation. ${ }^{22}$ Their applicability in purification is limited by these shortcomings. On the other hand, other biological affinity ligands such as nucleic acids, ${ }^{23}$ carbohydrates, ${ }^{24}$ chemical molecules, ${ }^{25}$ and linear, branched, and cyclic peptides, ${ }^{26}$ have low molecular weights, enhanced stability and more efficient screening strategies. Unique and short linear peptides have emerged with specific advantages, such as smaller size, lower cost, ease of synthesis, more amenable to be engineered at the molecular level, lower immunogenicity, and higher surface density, over antibodies.

The M13 phage-displayed random peptide library (M13 Ph.D. peptide library) provides a robust platform for seeking specific peptides with different molecular properties that bind to diverse targets. Nowadays, it is used in B-cell and T-cell epitope mapping, ${ }^{27}$ disease diagnosis, ${ }^{28}$ antiviral research, ${ }^{29}$ vaccine development, ${ }^{30}$ and peptide-mediated drug delivery system development. Furthermore, the target peptides identified using the M13 Ph.D. peptide library have potential use in 
biological affinity ligands, which play a key role in the purification of VLPs.

In this study, the Ph.D.-12 peptide library (New England Biolabs) was applied for the discovery of novel peptide ligands targeting the recombinant PCV2 Cap protein (r-Cap). Thus, a pET-28a-cap fusion proteins expression vector was built. The rCap (26 kDa) and amino acids 41-233 were expressed as their soluble form in E. coli BL21 (DE3) and purified using Ni-NTA column chromatography (Fig. 1a). To verify the reactogenicity of r-Cap, a western blot was performed using an anti-PCV2 Cap antibody (Fig. 1b). It was shown that the purified r-Cap had reactogenicity; thus, it was used as the target protein for further study.

We have biopanned a Ph.D.-12 peptide library against r-Cap to identify the linear peptide motifs that specifically bind to it. In brief, the r-Cap was immobilized onto $60 \times 15 \mathrm{~mm}$ Petri dishes and washed with TBST after blocking. The Ph.D.-12 peptide library $\left(1.5 \times 10^{11} \mathrm{pfu}\right)$ was added to the pre-coated Petri dishes, and the bound phage was eluted. After 3 rounds of biopanning, the peptides specific for r-Cap were identified. The operating process and statistical result after 3 rounds of biopanning are shown in Table $\mathrm{S} 1 . \dagger$ With an increase in the number of rounds of biopanning, stricter conditions for selection and elution were employed. As expected, the amount of enrichment of the eluted phage clones remained the same with the increase in the number of rounds of biopanning. Samples of the eluted phage from the third round of biopanning were used to purify the plaques of the individual phage clones and analyse the DNA sequence. In this case, 23 clones were DNA-sequenced and 14 readable sequences were obtained. The sequencing results showed that 9 of the 14 sequences were identical with the amino acid sequence of YHDCFSAGFCIG. Thus, from these 9 phage clones, the one named as $3 \mathrm{R} \# 2$ was selected for further characterization.

Indirect ELISA was performed to determine whether the 3R\#2 phage-displayed peptides had specifically bound to r-Cap. Thus, the $3 \mathrm{R} \# 2$ clones with different concentrations ranging from $10^{6}$ to $10^{11}$ pfu were incubated with $10 \mu \mathrm{g} \mathrm{mL}{ }^{-1}$ of r-Cap.

a)

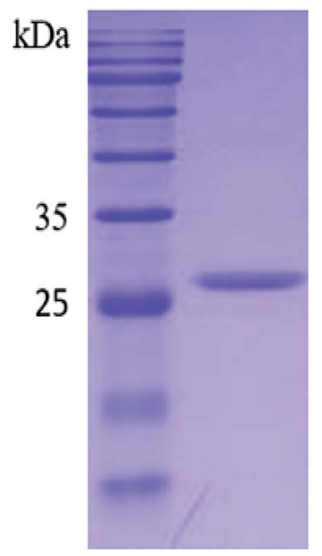

b)

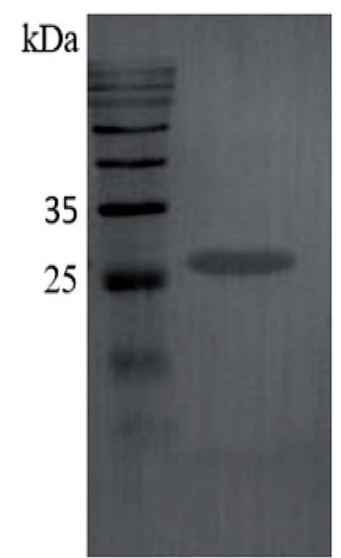

Fig. 1 SDS-PAGE (a) and western blot (b) of the purified recombinant Cap protein.
The results indicated that the highest ELISA signal was found in the presence of $10^{11} \mathrm{pfu} \mathrm{mL}^{-1}$ of the $3 \mathrm{R} \# 2$ clones, and the ELISA signal was reduced with a decrease in the amount of $3 \mathrm{R} \# 2$ clones (Fig. 2a). In addition, the ELISA signal sharply decreased at a concentration of $10^{10} \mathrm{pfu} \mathrm{mL}^{-1}$. To further study the effects of the r-Cap concentration on the ELISA signal, $10^{10} \mathrm{pfu} \mathrm{mL}^{-1}$ of the $3 \mathrm{R} \# 2$ phage clones was added to a pre-immobilized well with r-Cap at a variety of concentrations from $1.25 \mu \mathrm{g} \mathrm{mL}{ }^{-1}$ to 80 $\mu \mathrm{g} \mathrm{mL}^{-1}$ and measured using ELISA. The results showed that the binding ratio between the phage clones and r-Cap was highest at $40 \mu \mathrm{g} \mathrm{mL}^{-1}$ of r-Cap, and the ELISA signal increased with the increasing r-Cap concentration (Fig. 2b). As a negative control, wild type M13 phage did not bind to r-Cap (data not shown). From the above mentioned description, we found that the $3 \mathrm{R} \# 2$ phage-displayed peptides had specifically bound to r-Cap. Interestingly, this peptide was rich in hydrophobic amino acid residues such as Ile, Phe, Cys, and Ala, and the hydrophobicity reached up to $50 \%$ in total; this suggested that hydrophobic interactions were exploited in the binding of r-Cap. In addition, two cysteine residues at 4 and 10 were also found in the $3 \mathrm{R} \# 2$ sequence. Since $3 \mathrm{R} \# 2$ contains an even number of Cys, it may form a disulfide-bond linked beta structure, helical structures containing $\mathrm{S}-\mathrm{S}$ bonds or multiple thioether bonds. Finally, the sequence displayed on the $3 \mathrm{R} \# 2$ clones contains two Glys, which may stabilize the peptide conformation or flexibility.

A further surface plasmon resonance (SPR) experiment was performed with r-Cap and the $3 \mathrm{R} \# 2$ phage clones to measure their equilibrium dissociation binding affinity. Fig. 3a shows the equilibrium dissociation binding constant $\left(K_{\mathrm{d}}\right)$ of the $3 \mathrm{R} \# 2$ phage clones. In detail, the $K_{\mathrm{d}}$ value of $3 \mathrm{R} \# 2$ was $98.5 \mathrm{nM}$. The blocking effect of PCV2 positive serum (prepared by the Henan Provincial Key Laboratory of Animal Immunology) on the binding event between the $3 \mathrm{R} \# 2$ phage clones and r-Cap was also investigated. First, the PCV2 positive serum ranging from $0.1 \%$ to $1 \%$ was incubated at $10 \mu \mathrm{g} \mathrm{mL} \mathrm{m}^{-1}$ and $20 \mu \mathrm{g} \mathrm{mL}{ }^{-1}$ of r-Cap for $1 \mathrm{~h}$ at $37^{\circ} \mathrm{C}$. Second, $10^{11} \mathrm{pfu} \mathrm{mL} \mathrm{mL}^{-1}$ of the $3 \mathrm{R} \# 2$ clones was added to the wells for $1 \mathrm{~h}$ at $37{ }^{\circ} \mathrm{C}$. Third, the HRP-conjugated anti-M13 monoclonal antibody was added to the wells for $1 \mathrm{~h}$ at $37{ }^{\circ} \mathrm{C}$. Finally, the ELISA signals were measured at a wavelength of $450 \mathrm{~nm}$. Interestingly, the ELISA a)

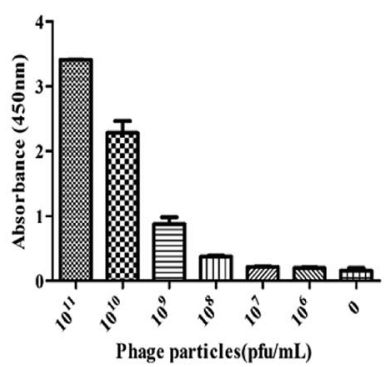

b)

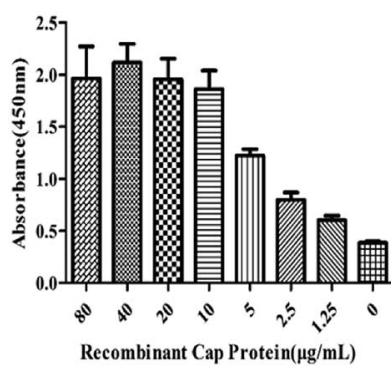

Fig. 2 The indirect ELISA assays. The effects of the 3R\#2 phage concentration $\left(0-10^{11}\right.$ pfu $\mathrm{mL}^{-1}$ ) (a) and r-Cap $\left(0-80 \mu \mathrm{g} \mathrm{mL}^{-1}\right.$ ) (b) on the ELISA signal. 
a)

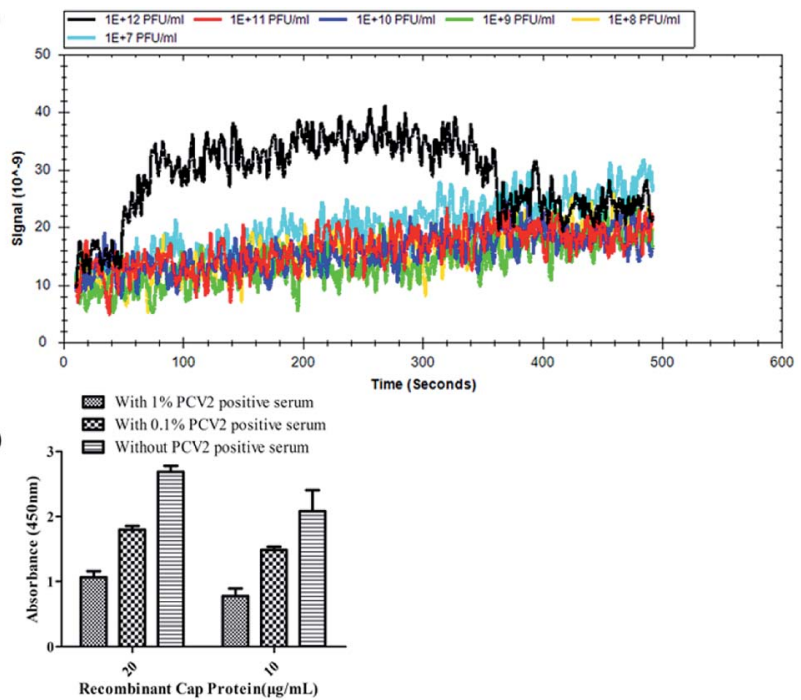

Fig. 3 The equilibrium dissociation binding constant $\left(K_{\mathrm{d}}\right)$ obtained by SPR (a) and serum blocking test (b).

signal of the $3 \mathrm{R} \# 2$ clones was rapidly decreased when the concentration of PCV2 positive serum was increased (Fig. 3b). As a consequence, we concluded that the $3 \mathrm{R} \# 2$ phage-displayed peptide screened using the Ph.D.-12 peptide library was found to be a potential affinity ligand for the purification of r-Cap; this suggested that it might have potential for PCV2 VLPs purification.

\section{Conclusions}

In this study, we have demonstrated, for the first time, the use of a phage display technique for biopanning novel peptide motifs that specifically recognize target proteins. The $3 \mathrm{R} \# 2$ peptide specific for target proteins had a sequence of YHDCFSAGFCIG, and ELISA and SPR assays were performed to evaluate the binding behaviour of this novel peptide. The results of the SPR assays show that the equilibrium dissociation binding constant of the $3 \mathrm{R} \# 2$ peptide was found to be in the nanomolar range for its target. In the serum blocking test, the OD value $(450 \mathrm{~nm})$ rapidly dropped as the concentration of the PCV2 positive serum increased. To the best of our knowledge, it may be conceivable that the newly identified recognition peptide provides new peptide-based affinity ligands for the purification of PCV2 VLPs. Because the phage used in this study can be generated using approximately 5 copies of the peptide per phage, the true $K_{\mathrm{d}}$ value of the free peptides for the target protein may be different due to the loss of the functional affinity. Further work will be required to explore the performance of synthetic peptides upon immobilization using MNPs.

\section{Acknowledgements}

The present study was funded by the Key Science and Technology Program of Henan Province (162102110136) and
Science-Technology Foundation for Outstanding Young Scientists of Henan Academy of Agricultural Sciences (2016YQ28).

\section{Notes and references}

1 Z. Afghah, B. Webb, X. J. Meng and S. Ramamoorthy, Vet. Microbiol., 2017, 206, 21-28.

2 G. Franzo, C. M. Tucciarone, M. Cecchinato and M. Drigo, Sci. Rep., 2016, 6, 39458.

3 C. Rosell, J. Segales, J. A. Ramos-Vara, J. M. Folch, G. M. Rodriguez-Arrioja, C. O. Duran, M. Balasch, J. PlanaDuran and M. Domingo, Vet. Rec., 2000, 146, 40-43.

4 J. Kim, H. K. Chung and C. Chae, Vet. J., 2003, 166, 251-256.

5 G. W. Stevenson, M. Kiupel, S. K. Mittal, J. Choi, K. S. Latimer and C. L. Kanitz, J. Vet. Diagn. Invest., 2001, 13, 57-62.

6 J. Kim, Y. Ha, K. Jung, C. Choi and C. Chae, Can. J. Vet. Res., 2004, 68, 218-221.

7 T. K. Jensen, H. Vigre, B. Svensmark and V. Bille-Hansen, J. Comp. Pathol., 2006, 135, 176-182.

8 R. Drolet, R. Larochelle, M. Morin, B. Delisle and R. Magar, Vet. Pathol., 2003, 40, 143-148.

9 A. K. Cheung, Virology, 2003, 313, 452-459.

10 T. Finsterbusch and A. Mankertz, Virus Res., 2009, 143, 177183.

11 K. P. Horlen, S. S. Dritz, J. C. Nietfeld, S. C. Henry, R. A. Hesse, R. Oberst, M. Hays, J. Anderson and R. R. Rowland, J. Am. Vet. Med. Assoc., 2008, 232, 906-912.

12 R. Khayat, N. Brunn, J. A. Speir, J. M. Hardham, R. G. Ankenbauer, A. Schneemann and J. E. Johnson, J. Virol., 2011, 85, 7856-7862.

13 Z. Liu, F. Guo, F. Wang, T. C. Li and W. Jiang, Structure, 2016, 24, 319-328.

14 N. M. Juhan, T. LeRoith, T. Opriessnig and X. J. Meng, Virus Res., 2010, 147, 60-66.

15 J. Liu, I. Chen and J. Kwang, J. Virol., 2005, 79, 8262-8274.

16 P. C. Wu, W. L. Lin, C. M. Wu, J. N. Chi, M. S. Chien and C. Huang, Appl. Microbiol. Biotechnol., 2012, 95, 15011507.

17 L. J. Liu, T. Suzuki, H. Tsunemitsu, M. Kataoka, N. Ngata, N. Takeda, T. Wakita, T. Miyamura and T. C. Li, Arch. Virol., 2008, 153, 2291-2295.

18 S. A. Bucarey, J. Noriega, P. Reyes, C. Tapia, L. Saenz, A. Zuniga and J. A. Tobar, Vaccine, 2009, 27, 5781-5790.

19 M. Zaveckas, S. Snipaitis, H. Pesliakas, J. Nainys and A. Gedvilaite, J. Chromatogr. B: Anal. Technol. Biomed. Life Sci., 2015, 991, 21-28.

20 S. Yang, H. Ouyang, X. Su, H. Gao, W. Kong, M. Wang, Q. Shu and Z. Fu, Biosens. Bioelectron., 2016, 78, 174-180.

21 W. Wang, X. Ji, H. B. Na, M. Safi, A. Smith, G. Palui, J. M. Perez and H. Mattoussi, Langmuir, 2014, 30, 6197-6208.

22 C. S. Fernandes, I. Barbosa, R. Castro, A. S. Pina, A. S. Coroadinha, A. Barbas and A. C. Roque, Biotechnol. J., 2016, 11, 1513-1524.

23 D. Cheng, M. Yu, F. Fu, W. Han, G. Li, J. Xie, Y. Song, M. T. Swihart and E. Song, Anal. Chem., 2016, 88, 820-825.

24 K. El-Boubbou, C. Gruden and X. Huang, J. Am. Chem. Soc., 2007, 129, 13392-13393. 
25 X. Yang, X. Zhou, M. Zhu and D. Xing, Biosens. Bioelectron., 2016, 91, 238-245.

26 F. Y. Kuo, W. L. Lin and Y. C. Chen, Nanoscale, 2016, 8, 92179225.

27 C. H. Wu, I. J. Liu, R. M. Lu and H. C. Wu, J. Biomed. Sci., 2016, 23, 8.
28 B. Bakhshinejad and M. Sadeghizadeh, World J. Gastroenterol., 2014, 20, 11671-11683.

29 Y. He, X. Ye, P. Tiollais, J. Zhang, J. Zhang, J. Liu and Y. Xie, Acta Biochim. Biophys. Sin., 2014, 46, 691-698.

30 W. S. Tan and K. L. Ho, World J. Gastroenterol., 2014, 20, 11650-11670. 